\title{
Cluster Analysis of Symptoms Among Patients with Upper Extremity Musculoskeletal Disorders
}

\author{
Judith E. Gold · George Piligian · Joseph J. Glutting • \\ Alexandra Hanlon • Monique H. W. Frings-Dresen • \\ Judith K. Sluiter
}

Published online: 23 April 2010

(c) The Author(s) 2010. This article is published with open access at Springerlink.com

\begin{abstract}
Introduction Some musculoskeletal disorders of the upper extremity are not readily classified. The study objective was to determine if there were symptom patterns in self-identified repetitive strain injury (RSI) patients. Methods Members $(n=700)$ of the Dutch RSI Patients Association filled out a detailed symptom questionnaire.
\end{abstract}

J. E. Gold $(\bowtie) \cdot$ A. Hanlon

Department of Public Health, Temple University, 1301 Cecil B.

Moore Avenue, Philadelphia, PA 19122, USA

e-mail: Judith.Gold@temple.edu; jgold@temple.edu

A. Hanlon

e-mail: alhanlon@nursing.upenn.edu

G. Piligian

Program to Prevent and Treat Work-Related Musculoskeletal

Disorders, Irving J. Selikoff Center for Occupational and

Environmental Medicine, Mt. Sinai Medical Center, One

Gustave Levy Place, New York, NY 10029-6574, USA

e-mail: george.piligian@mssm.edu

\section{J. J. Glutting}

School of Education, University of Delaware, Newark, DE 19716, USA

e-mail: glutting@udel.edu

A. Hanlon

School of Nursing, University of Pennsylvania, 418 Curie

Boulevard/Room 479, Philadelphia, PA 19104, USA

M. H. W. Frings-Dresen · J. K. Sluiter

Academic Medical Center, Coronel Institute of Occupational

Health, University of Amsterdam, 1100 DE Amsterdam,

The Netherlands

e-mail: m.frings@amc.uva.nl

J. K. Sluiter

e-mail: j.sluiter@amc.uva.nl
Factor analysis followed by cluster analysis grouped correlated symptoms. Results Eight clusters, based largely on symptom severity and quality were formulated. All but one cluster showed diffuse symptoms; the exception was characterized by bilateral symptoms of stiffness and aching pain in the shoulder/neck. Conclusions Case definitions which localize upper extremity musculoskeletal disorders to a specific anatomical area may be incomplete. Future clustering studies should rely on both signs and symptoms. Data could be collected from health care providers prospectively to determine the possible prognostic value of the identified clusters with respect to natural history, chronicity, and return to work.

Keywords Case definition - Classification - MSD · RSI $\cdot$ Non-specific $\cdot$ Factor analysis

\section{Introduction}

Musculoskeletal disorders accounted for 30 percent of the approximately 1.2 million workplace illnesses and injuries reported in 2006 in the United States [1]. A general population study in The Netherlands found that those with elbow or wrist/hand symptoms were over two times as likely to be disabled from work than those without such symptoms [2]. Similar results held for those with neck, shoulder or upper back complaints.

Although prevalent and potentially disabling, some disorders of the upper extremity are not readily classified. Both the Harrington et al. [3] and Sluiter et al. [4] criteria documents for clinical diagnoses or epidemiologic case definitions of upper extremity musculoskeletal disorders (UEMSDs) recognize a non-specific disorder. The diagnosis or characterization of a non-specific UEMSD, variously 
called "non-specific diffuse forearm pain", "repetitive strain injury" (RSI), "cumulative trauma disorder" (CTD), etc. may be one of exclusion of more localized disorders (e.g., carpal tunnel syndrome, de Quervain's disease). However, this non-specific disorder may in fact represent several separate disorders. This may have implications for prevention and treatment.

Subtypes in diseases including complex regional pain syndrome [5, 6], fibromyalgia [7], and Alzheimer's disease [8-10] have been explored through factor analysis and cluster analysis. A similar analysis of patients with UEMSDs was possible through a questionnaire administered in 1999 through the Dutch RSI Patients Association ( $n=806)$ from which detailed information on symptom location, quality, and intensity was obtained. The objective of this study was to determine if there were patterns of symptoms in these patients (who identified themselves as having RSI) that tended to occur together, with a long-term goal of discovering new upper extremity syndromes.

Specific UEMSDs include those that by definition are localized to particular anatomical regions. For instance, carpal tunnel syndrome as a compression of the median nerve in the carpal tunnel results in symptoms in the hand/ wrist, symptoms in epicondylitis are confined to the elbow, and rotator cuff tendinitis is characterized by complaints in the shoulder region. Similarly, specific UEMSDs may be distinguished by quality of symptoms experienced. That is, the predominant symptom in the various localized tendinopathies is activity dependent pain, whereas paraesthesias and numbness are not likely in the absence of neuropathology. These distinguishing features of specific UEMSDs informed the study hypotheses, which were explored through factor analysis and subsequent cluster analysis of the patient association database. It was hypothesized that:

1. distinct UEMSD syndromes would be identified based on localization of symptoms affecting the following upper extremity regions:
a. hand/wrist
b. elbow
c. shoulder
d. neck

2. further discrimination of syndromes would be possible within the above distinct anatomical groups through classifying by present qualities of symptoms (pain, stiffness, paraesthesia, etc.) and by intensity of patient complaint.

Additionally, clusters were examined for their differences with respect to gender and age proportion, percentage of those working, and overall course of symptoms.

\section{Methods}

\section{Description of Dataset}

In the Netherlands, patients with the same disease are allowed and administratively helped by Governmental Services to join and start a society. Everyone who is diagnosed with or believes that they have RSI is free to become a member of the RSI-patient society. In February 1999, all registered 1,700 members of the Dutch National RSI-patient society were sent a questionnaire. All members received this survey with a response envelope at their home address as sent from the secretariat of the society. An accompanying letter was included from the researchers and the RSI-patient society board. Additionally, a general reminder was posted in the society's official newsletter. A total of $53 \%$ responded. Five questionnaires were returned unopened, and 92 questionnaires were filled in insufficiently for analyses. Therefore, data from 806 questionnaires could be included in the analyses.

This study was conducted in accordance with the laws of the country in which it was performed. In The Netherlands, it is not necessary for study subjects to fill out a consent form in de-identified cross-sectional survey research inquiring about health status. If subjects do not want to participate, they just will not fill in the questionnaire.

The questionnaire included demographic variables such as gender, age, height and weight. Work status was indicated as "full time", "part time", "working with adaptations", "work pension" or "not working". Other items included number of months since symptoms began, and course of complaints. Subjects were asked to assess the level of current complaints as compared with the level at symptom onset. Respondents could choose "no change", "getting better", "getting worse", "getting better but more extensive", and "getting worse and more extensive". Symptom location, quality and intensity were also ascertained.

\section{Description of Candidate Variables for Factor Analysis}

Questionnaire respondents characterized their current or recent symptoms through 118 variables; these formed the candidates for factoring. These variables were of three types, distinguished by what attributes they were measuring and the scale by which the attributes were measured. Attributes included:

1. current symptom quality intensity (1-10 scale, $2=$ "just sensible", $10=$ "maximal pain") was ascertained separately for eleven body regions (neck, right(R)/left(L) shoulder, R/L upper arm, R/L elbow, $\mathrm{R} / \mathrm{L}$ lower arm, and R/L wrist/hand). Possible qualities 
included: dull aching, stabbing/sharp, burning, toothache-like, or shooting pain, stiffness, paraesthesias, numbness, and coldness.

2. duration of symptoms in the last week by body region. Possible regions included: neck, shoulder, upper arm, elbow, lower arm, and hand/wrist. The left or right side of each region as well as dorsal or ventral (front or back) area could be specified. Possible duration categories included: 0 days, 1-2 days, 3-6 days and every day (4 point scale).

3. severity of symptoms in the last week. Questions included: severity of pain in the neck/shoulder/arm/ hand, severity of pain in the neck/shoulder/arm/hand during a specific actvivity, severity of paraesthesias in the shoulder/arm/hand, severity of weakness in the neck/shoulder/arm/hand, and severity of stiffness in the neck/shoulder/arm/hand. Possible answers included: none, mild, average, severe, and extreme (5 point scale).

\section{Factoring Procedure}

The original 118 items were reduced using principal components analysis (PCA) as a first step in describing and identifying the clusters. Of the $n=806$ individuals with usable questionnaires, twenty-nine subjects who reported diabetes, thyroid problems or rheumatoid arthritis were eliminated from the analysis to avoid confounding by these co-morbid conditions. This yielded a total of 777 subjects for factor analysis. Of these, 701 had complete data on the 118 items. One subject was later deleted at random during the clustering procedures so that the sample could be randomly split into five subsamples for replication analyses [11]. As a result, the final $n=700$.

One of the more critical decisions in a PCA is to determine the correct number of factors to retain and rotate [12-14]. The most common rule is to retain factors when eigenvalues are $\geq 1.0$. This solitary criterion is the default procedure in most statistical packages. The shortcoming is that implementation of solitary criteria tends to under- or overestimate the number of true latent dimensions [15-17]. Accordingly, each model was evaluated against the following four rules: (a) scree [18], (b) Glorfeld's (1995) extension of parallel analysis (PA) [19, 20], (c) interpretability [12, 15], and (d) internal-consistency reliabilities required to be greater, or equal to, 0.70 $[21,22]$. Although all four rules were applied, special emphasis was placed on PA and the scree test because results from several investigations demonstrated that PA is the best method for determining the correct number of factors to accept and that the scree test is a useful adjunct $[16,17,19,23]$.
Clustering Procedure

Upon identifying the underlying principal components, profiles (also called profile types or clusters) from the 700 participants were sorted according to level, shape, and dispersion among the factors. All factors were converted to $z$-scores $($ mean $=0.0$, standard deviation $=1.0)$ prior to analysis in order to equalize their variances. Otherwise, scores with larger variances would contribute disproportionately to the formation of clusters [24]. The analyses required that individuals within each group be maximally similar to one another (maximum homogeneity) and maximally dissimilar to those in other groups (minimum overlap). The groups of similar profiles were also required to be reasonably replicable across groups rather than spurious mergers, as would occur by chance [25]. To this end, the sample was split into four random subsamples, each composed of 150 participants.

Cluster analysis was used to sort the 700 profiles [26, 27]. After evaluating numerous clustering algorithms, Ward's [28] minimum-variance procedure was determined to best satisfy the research goals for first-stage clustering. The procedure began with Ward's technique to produce first-stage clusters for each of the four independent subsamples. Three percent of the participants were trimmed from each of the four, first-stage samples, and thus were eliminated as outliers from the clustering process. Clustering during the second-stage analysis was completed again using Ward's technique. Group centroids from the second-stage solution served as starting points for the thirdstage, iterative-partitioning analysis conducted using K-means passes.

Results from the final solution were compared along three internal criteria. First, the overall solution was required to show a replicability rate $\geq 75 \%$ for the absorption of firststage clusters into the final, third-stage taxonomy. Because cluster solutions may be unstable, replication can validate their integrity [29]. More specifically, a Monte Carlo simulation demonstrated that analyses are likely to identify the true number of clusters when replication rates are $\geq 75 \%$ [11]. Second, the typology was required to yield an average within-profile type homogeneity coefficient, $\bar{H} \geq 0.60$ [30]. This property has been referred to as internal cohesion [31]. It requires small score dispersions within clusters and, thereby, for individuals within a cluster to be maximally similar. The third criterion required the typology to show external isolation [31]. This property dictates large score dispersions between clusters so that the clusters are maximally dissimilar from one another. Cattell's $r_{p}$ coefficient [32] was calculated between profile types as our measure of external isolation and the typology needed to provide an average between-profile-types similarity coefficient, $\bar{r}_{p} \leq 0.40$ [32]. $\bar{H}$ and $r_{p}$ are each sensitive to similar profile 
levels and shapes, where a value of 1.00 indicates profiles identical in level and shape, 0.0 indicates chance similarity based on the full sample, and negative values indicate gross dissimilarity. Minimum criterion values have been established empirically for $\bar{H}$ and $r_{p}$ ( $\geq 0.60$ and $\leq 0.40$, respectively) based on clustering and classification studies conducted with random samples larger than the current one, as well as with epidemiologically-representative data sets [33-36].

\section{Statistical Analysis}

The clusters were compared with regard to gender, age, percentage working, and course of complaints. Subjects were regarded as working if they denoted their work status as full time, part time, or working with adaptations. Those on a work pension were regarded as not working. Symptom course was compared across three groups: (1) no change, (2) better, and (3) worse, or worse and more extensive, or better but more extensive. The Pearson's chi-square test was used to separately compare the proportion of those working, percentage female, and distribution of course of symptoms within each cluster to that of the cohort overall. A one-way ANOVA followed by the Games-Howell posthoc test (used because of unequal $n$ in the clusters) determined differences among clusters in number of months since symptom onset and age. A $P$-value of $\leq 0.05$ was regarded as statistically significant.

Clusters were regarded as mild if all factors were $\leq 0.3$ standard deviations (SD) from the cohort mean, and moderate if all factors were $<1.5 \mathrm{SD}$ from the mean. If any factor in the cluster was $\geq 1.5 \mathrm{SD}$ from the mean, the cluster was labeled severe. If any factor in the cluster was $\geq 5 \mathrm{SD}$ from the mean, the cluster was labeled extreme. The interpretation of these levels was empirically based.

\section{Results}

Demographic Characteristics of Clustered Subjects

The analysis cohort consisted of $n=700$ individuals of whom $n=462(66 \%)$ were females. Mean age was 37.6 $(\mathrm{SD}=8.6)$ years. Eighty-four percent had been diagnosed by a physician. Just under half $(n=321,46 \%)$ listed their current occupation as "administrative activities/office work (secretary, accountant)" or "journalist/translator/text writer". Information technology (IT) workers and those in industry/performing heavy physical work each comprised approximately $15 \%$ of respondents. Sixty percent $(n=$ 417) were working at least part-time.
Morbidity Characteristics of Clustered Subjects

The 700 subjects who were clustered had mean values of symptom intensity just over "just sensible" of these types of symptoms: dull aching pain and stiffness in the neck and right shoulder, dull aching right lower arm pain, and right wrist symptoms including dull aching pain, stiffness, paraesthesias, and a cold feeling (Table 1). Additionally, the average participant experienced pain for at least 1-2 days during the previous week in each body region under question. Symptoms that were experienced for the greatest duration during the last week (between 1-2 and 3-6 days) included those on the right-side dorsal portion of the shoulder, those in the right dorsum of wrists, hands and fingers and those in the neck. Severity of pain during the last week was "average" in the neck/shoulder/arm/hand (mean $=3.0, \mathrm{SD}=1.0$ ) and worse than average in the same region during specific activities (mean $=3.6, \mathrm{SD}=$ 1.2) in the last week. Mean severity of paraesthesias, weakness, and stiffness during the last week was between "mild" and "average".

The average duration of symptoms was 39 months $(\mathrm{SD}=37.4)$. Somewhat over one-third of the respondents characterized the course of their symptoms when compared with symptom onset as "worse and more extensive", and a slightly smaller number reported that their symptoms were improving. Approximately one-fifth stated that their complaints were "less but more extensive".

\section{Factor Results}

Fourteen factors were interpreted according to the magnitude and meaning of their salient pattern coefficients. All coefficients greater than 0.45 were considered appreciable. Names for the 14 dimensions are provided below. Corresponding internal-consistency reliabilities (i.e., alpha $(\alpha)$

Table 1 Mean intensity by present symptom quality in $n=700$ members of the Dutch RSI Patients Association

\begin{tabular}{lll}
\hline Variable descriptor & Mean & SD \\
\hline Dull/aching neck pain & 3.5 & 2.8 \\
Stiffness neck & 3.8 & 2.8 \\
Dull/aching right (R) shoulder pain & 3.6 & 2.8 \\
Stiffness R shoulder & 3.2 & 2.7 \\
Dull/aching lower R arm pain & 3.3 & 2.6 \\
Dull/aching R wrist/hand pain & 3.7 & 2.8 \\
Stiffness R wrist/hand & 3.1 & 2.7 \\
Paraesthesias in R wrist/hand & 3.2 & 2.7 \\
Cold feeling in R wrist/hand & 3.1 & 2.9 \\
\hline
\end{tabular}

Means of 3 and above were included in this table (scale 1-10: $1=$ none, $2=$ just sensible, $10=$ maximal pain) 
coefficients) are presented in parentheses: (1) left-sided shoulder through hand/wrist symptoms, chronic in lower arm $(\alpha=0.92)$, (2) bilateral proximal (elbow, shoulder, and neck) cold and numbness $(\alpha=0.91)$, (3) bilateral diffuse (defined as "neck-to-hand/wrist") "like a toothache" pain $(\alpha=0.93)$, (4) chronic bilateral stiff aching neck/shoulder $(\alpha=0.84)$, (5) right-sided diffuse stabbing shooting pain $(\alpha=0.89)$, (6) chronic (dorsal and ventral) wrist/hand/finger symptoms $(\alpha=0.87)$, (7) bilateral diffuse burning pain $(\alpha=0.89)$, (8) chronic bilateral distal (lower arm through hand/wrist) numbness and paraesthesias $(\alpha=0.86)$, (9) chronic bilateral (dorsal and ventral) upper arm symptoms $(\alpha=0.83)$, (10) bilateral arm (NOT neck and shoulder) stiffness $(\alpha=0.85)$, (11) bilateral proximal (neck-to-elbow) paraesthesias $(\alpha=0.88$ ), (12) chronic bilateral shooting, stabbing, aching elbow pain $(\alpha=0.86)$, (13) chronic bilateral lower arm aching pain $(\alpha=0.73)$, (14) right-sided upper-to-lower arm aching pain $(\alpha=0.79)$. Associations among the 14 retained components were low. Only one of the possible 91 nonredundant correlations was $\geq 0.40$ (i.e., $14(11-1) /$ $2=91$ ). This latter finding indicates that the 14 dimensions are essentially orthogonal and share less than $16 \%$ percent of their variance in common with one another (i.e., $0.40^{2}=0.16$ )

\section{Cluster Results}

First-stage clustering produced 41 clusters in total (an average of 8.2 profile groups per analysis). These were submitted to second-stage agglomerative clustering based on a $41 \times 41$ similarity matrix and the solution at all hierarchical steps was evaluated against the stated internal criteria. The second-stage, eight-cluster solution was the only one to satisfy all three of the internal criteria.
Therefore, it was submitted to a third-stage, iterative-partitioning analysis which also resulted in a final typology of eight clusters.

Table 2 displays, for each of the cluster types, its estimated prevalence in the population, average coefficient for within-type homogeneity, between-types similarity, and replication rate. The average $\bar{H}$ value of 0.99 is well above its a priori criterion of $\geq 0.60$ and the average $r_{p}$ value of -0.095 satisfies the $\leq 0.40$ criterion. The types replicated $90.6 \%$ of the time across the four independent experiments. Therefore, the obtained, eight-cluster solution also satisfied its a priori replication criterion of $\geq 75 \%$.

In Table 3, each cluster is presented in terms of number of standard deviations ( $z$-score) from the mean on a per factor basis. It is important to remember that the mean (where $z$-score $=0$ ) symptomatic profile of the group under study consists of dull/aching neck and right arm (shoulder through wrist), stiff neck, shoulder, and wrist, and paraesthesias and coldness in the wrist (Table 1). Also, subjects were symptomatic in the last week, particularly in the right neck, shoulder and hand/fingers, with severity of pain reported as "average".

Cluster 1 consists of most factors between 0.5 and 1.0 standard deviations below the mean value for the cohort, while Cluster 8 is characterized by all but one factor being one or more standard deviations above the mean (Table 3). Again, a z-score of zero does not denote no symptoms, but rather the mean value of symptoms in the cohort.

\section{Cluster Membership (Tables 4, 5)}

\section{Cluster 1: Mild Diffuse MSD (Prevalence $=37.9 \%$ )}

This group was characterized by mild symptoms in the upper extremity with no one anatomical area predominating.

Table 2 Cluster prevalences and statistical characteristics $(n=700)$

\begin{tabular}{llllll}
\hline $\begin{array}{l}\text { Cluster } \\
\text { number }\end{array}$ & $\begin{array}{l}\text { \% Population } \\
\text { prevalence }\end{array}$ & $\begin{array}{l}\text { Internal } \\
\text { cohesion }(H)\end{array}$ & $\begin{array}{l}\text { External } \\
\text { isolation }\left(r_{p}\right)\end{array}$ & $\begin{array}{l}\text { \% Replicability across } \\
\text { first-order clusters }\end{array}$ & Descriptive name \\
\hline 1 & 37.86 & 0.99 & -0.075 & 100 & Mild diffuse MSD \\
2 & 25.43 & 0.99 & 0.084 & 80 & Mild bilateral aching stiff neck and shoulders \\
3 & 15.56 & 0.99 & 0.106 & 100 & Moderate bilateral arm and wrist/hand/finger MSD \\
4 & 4.57 & 0.99 & -0.067 & 60 & Severe diffuse MSD \\
5 & 11.00 & 0.99 & 0.130 & 80 & Moderate MSD with highlighted bilateral elbow \\
& & & & & Shooting stabbing pain \\
6 & 2.86 & 0.99 & -0.014 & 80 & Severe diffuse MSD with highlighted coldness \\
& & & & numbness, and paraesthesias (CNP) \\
7 & 1.86 & 0.99 & -0.386 & 80 & Extreme diffuse MSD with highlighted pain \\
8 & 0.86 & 0.99 & -0.537 & 60 &
\end{tabular}

H, within-profile type homogeneity coefficient; MSD, musculoskeletal disorder; $r_{p}$, between-profile types dissimilarity coefficient 
Table 3 Mean score patterns for cluster types by factors, expressed as $z$-scores

\begin{tabular}{|c|c|c|c|c|c|c|c|c|c|c|c|c|c|c|}
\hline \multirow[t]{2}{*}{ Cluster number } & \multicolumn{14}{|l|}{ Factor } \\
\hline & 1 & 2 & 3 & 4 & 5 & 6 & 7 & 8 & 9 & 10 & 11 & 12 & 13 & 14 \\
\hline 1 & -0.6 & -0.3 & -0.3 & -0.8 & -0.5 & -0.6 & -0.5 & -0.6 & -0.6 & -0.5 & -0.3 & -0.6 & -0.8 & -0.7 \\
\hline 2 & -0.2 & -0.1 & -0.2 & 0.4 & -0.2 & -0.2 & -0.3 & -0.3 & -0.2 & -0.2 & -0.3 & -0.3 & -0.1 & -0.1 \\
\hline 3 & 0.2 & -0.2 & 0.0 & 0.1 & -0.2 & 1.1 & 0.2 & 0.3 & 0.9 & 0.0 & 0.0 & 0.0 & 0.7 & 0.1 \\
\hline 4 & 2.1 & 0.4 & 0.2 & 1.0 & 1.5 & 1.4 & 2.0 & 1.9 & 1.2 & 1.7 & 1.3 & 1.8 & 1.5 & 1.6 \\
\hline 5 & 0.5 & 0.0 & 0.1 & 0.5 & 0.9 & 0.2 & 0.4 & 0.5 & 0.0 & 0.7 & -0.1 & 1.2 & 0.7 & 1.0 \\
\hline 6 & 0.6 & 2.6 & 1.2 & 1.2 & 1.6 & 0.2 & 1.2 & 1.2 & 0.8 & 0.7 & 2.1 & 0.6 & 0.5 & 0.9 \\
\hline 7 & 3.1 & 1.5 & 5.2 & 1.5 & 2.6 & 1.4 & 2.1 & 1.5 & 1.6 & 2.4 & 1.9 & 2.8 & 1.6 & 2.1 \\
\hline 8 & 2.1 & 6.7 & 1.8 & 1.8 & 2.3 & 0.8 & 1.7 & 3.4 & 1.3 & 3.1 & 5.6 & 1.3 & 1.5 & 2.1 \\
\hline
\end{tabular}

See text for description of cluster and factor numbers

Table 4 Cluster description, symptom intensity and localization

\begin{tabular}{|c|c|c|c|}
\hline Cluster & Description & $\begin{array}{l}\text { Symptom intensity } \\
\text { (see text) }\end{array}$ & $\begin{array}{l}\text { Symptom } \\
\text { localization }\end{array}$ \\
\hline 1 & Diffuse symptoms & Mild & $\mathrm{N}$ \\
\hline 2 & Bilateral stiff aching neck/shoulder symptoms & Mild & $\mathrm{Y}$ \\
\hline 3 & $\begin{array}{l}\text { Chronic bilateral upper arm symptoms. Also, chronic bilateral hand/wrist/finger } \\
\text { symptoms }\end{array}$ & Moderate & $\mathrm{N}$ \\
\hline 4 & $\begin{array}{l}\text { Bilateral overall burning pain with distal numbness and paraesthesias. Also, } \\
\text { bilateral elbow symptoms, and arm stiffness and ache }\end{array}$ & Severe & $\mathrm{N}$ \\
\hline 5 & $\begin{array}{l}\text { Chronic bilateral elbow pain, predominantly right-sided aching arm and diffuse } \\
\text { shooting/stabbing pain. Also, arm stiffness }\end{array}$ & Moderate & $\mathrm{N}$ \\
\hline 6 & $\begin{array}{l}\text { Chronic bilateral overall coldness, numbness, and paraesthesias. Also, overall } \\
\text { pain and stiffness }\end{array}$ & Severe & $\mathrm{N}$ \\
\hline 7 & $\begin{array}{l}\text { Chronic bilateral overall aching, toothache, stabbing/sharp, burning pain with } \\
\text { stiffness and numbness }\end{array}$ & Extreme & $\mathrm{N}$ \\
\hline 8 & $\begin{array}{l}\text { Chronic bilateral overall symptoms, dominated by coldness, numbness and } \\
\text { paraesthesias. Bilateral stiffness, which is worse in the arms through hands } \\
\text { than in the neck and shoulder. Chronic bilateral overall burning, toothache, } \\
\text { shooting/stabbing, aching pain }\end{array}$ & Extreme & $\mathrm{N}$ \\
\hline
\end{tabular}

A significantly greater proportion of subjects in this group were working $(75.5 \%)$ than in the cohort overall. Their symptom course was significantly different from that of the entire population, with almost half $(47 \%)$ reporting fewer symptoms from symptom onset through the date of filling out the questionnaire. They had symptoms for a mean of 2.5 years; this was a shorter duration than most of the other clusters (see below). Also, significantly more of these cluster members were male $(44.9 \%)$ than in the other clusters.

Cluster 2: Mild Bilateral Aching Stiff Neck and Shoulders (Prevalence $=25.4 \%)$

These cluster members had localized bilateral aching and stiffness in the neck and shoulder. The mean duration of symptoms was significantly greater than that of cluster 1
(40.6 vs. 30.3 months). Other characteristics were similar to that of the overall population.

Cluster 3: Moderate Bilateral Arm and Wrist/Hand/Finger MSD (Prevalence $=15.5 \%)$

These individuals had chronic bilateral upper arm and hand/wrist/finger symptoms. Significantly fewer were working $(46 \%)$ in comparison to the cohort as a whole. Seventy-four percent characterized their symptoms as getting worse or more widespread.

\section{Cluster 4: Severe Diffuse MSD (Prevalence $=4.6 \%$ )}

These cluster members had bilateral widespread symptoms of burning pain combined with distal numbness. Bilateral elbow symptoms and aching stiff arms were also prominent. 
Table 5 Demographics, percentage working, mean symptom duration and symptom course, by cluster $(n=700)$

\begin{tabular}{|c|c|c|c|c|c|c|c|c|}
\hline \multirow[t]{2}{*}{ Cluster } & \multirow[t]{2}{*}{$n(\%)$} & \multirow{2}{*}{$\begin{array}{l}\text { Working } \\
n(\%)\end{array}$} & \multirow{2}{*}{$\begin{array}{l}\text { Months with } \\
\text { symptoms } \\
\text { (mean [SD]) }\end{array}$} & \multicolumn{3}{|c|}{ Symptom course } & \multirow{2}{*}{$\begin{array}{l}\text { Female } \\
n(\%)\end{array}$} & \multirow{2}{*}{$\begin{array}{l}\text { Age in year } \\
\text { (mean [SD]) }\end{array}$} \\
\hline & & & & $\begin{array}{l}\text { No change } \\
n(\%)\end{array}$ & $\begin{array}{l}\text { Worse/worse \& more } \\
\text { extensive or better but } \\
\text { more extensive } n(\%)\end{array}$ & $\begin{array}{l}\text { Better } \\
n(\%)\end{array}$ & & \\
\hline 1 & 265 (37.9) & $200 *(75.5)$ & $30.3(25.5)$ & $14^{++}(5.3)$ & $126(48.1)$ & $122(46.6)$ & $146^{*}(55.1)$ & $37.3(8.5)$ \\
\hline 2 & $178(25.4)$ & 103 (57.9) & $40.6^{+}(38.4)$ & $11(6.2)$ & $123(69.5)$ & $43(24.3)$ & $123(69.1)$ & $37.6(8.4)$ \\
\hline 3 & 109 (15.6) & $50 *(45.9)$ & $45.1(49.6)$ & $4(3.7)$ & 79 (73.8) & $24(22.4)$ & 79 (72.5) & $40.0(8.9)$ \\
\hline 4 & $32(4.6)$ & $18(56.3)$ & $60.7^{+}(45.2)$ & $1(3.1)$ & $25(78.1)$ & $6(18.8)$ & $24(75.0)$ & $37.4(9.8)$ \\
\hline 5 & 77 (11.0) & $33 *(42.9)$ & $44.1(38.7)$ & $3^{++}(3.9)$ & $62(82.6)$ & $11(14.5)$ & 55 (71.4) & $36.4(8.3)$ \\
\hline 6 & $20(2.9)$ & $9(45.0)$ & $49.6(46.3)$ & $1(5.0)$ & $13(65.0)$ & $6(30.0)$ & $17(85.0)$ & $35.8(9.8)$ \\
\hline 7 & 13 (1.9) & $1 *(7.7)$ & $56.1(26.9)$ & $3^{++}(23.1)$ & $8(61.5)$ & $2(15.4)$ & $13 *(100.0)$ & $37.0(7.8)$ \\
\hline 8 & $6(0.9)$ & $3(50.0)$ & $27.8(20.3)$ & $1(16.7)$ & $5(83.3)$ & 0 & $5(83.3)$ & $33.1(9.6)$ \\
\hline Overall & 700 & 417 (59.6) & $39.1(37.4)$ & $38(5.5)$ & 441 (63.6) & $214(30.9)$ & $462(66.0)$ & $37.6(8.6)$ \\
\hline
\end{tabular}

* Pearson's chi-square test, $P \leq 0.05$, cluster proportion significantly different from overall proportion

+ ANOVA with Games-Howell post-hoc test, $P \leq 0.05$, significantly different from cluster 1 in multiple comparisons

${ }^{++}$Pearson's chi-square test, $P \leq 0.05$, cluster symptom course proportion significantly different from overall proportion

Duration of symptoms (60.7 months) was longer than in any other cluster, and significantly different in duration than cluster 1. Almost sixty percent of these subjects reported their symptom course as "worse and more extensive." Three-quarters of the subjects were female.

\section{Cluster 5: Moderate MSD with Highlighted Bilateral Elbow Shooting Stabbing Pain (Prevalence $=11.0 \%$ )}

This group experienced chronic bilateral elbow symptoms, with diffuse right-sided arm pain. Fewer subjects were working in comparison to the cohort as a whole $(P \leq$ $0.05)$, although $44 \%$ of this group was working. Most $(83 \%)$ reported worsening or spreading symptoms.

Cluster 6: Severe Diffuse MSD with Highlighted Coldness, Numbness, and Paraesthesias (CNP) (Prevalence $=2.9 \%)$

Chronic overall coldness, numbness, and paraesthesias characterized this cluster with lesser intensities of pain and stiffness. Although not statistically significant due to low power, almost all $(85 \%)$ of the members were female. Slightly fewer than half of the cluster members were not working.

\section{Cluster 7: Extreme Diffuse MSD with Highlighted Pain $($ Prevalence $=1.9 \%)$}

This group was characterized by high intensity chronic bilateral symptoms throughout the upper extremity. Symptom qualities included aching, burning, "like a toothache", and stabbing/sharp pain as well as stiffness and numbness. Although there were only 13 members in this cluster, several of the examined characteristic proportions were significantly different from that of the overall patient population. Only one of the 13 cluster members was working $(P \leq 0.05)$ and all were females $(P \leq 0.05)$. Their symptom course was significantly different from that of the entire cohort with almost one-fourth reporting no change in their symptom course. Non-significantly different from the mean symptom duration of the cohort as a whole, their symptom duration was almost 5 years.

\section{Cluster 8: Extreme Diffuse MSD with Highlighted CNP (Prevalence 0.9\%)}

These individuals experienced a great intensity of chronic bilateral symptoms. Coldness, numbness, and paraesthesias were predominant. Stiffness, which was worse distally than proximally, and overall pain were also experienced. Although the sample size was small, interestingly, $50 \%$ of these individuals were working and they had the shortest mean symptom duration (27.8 months) of any cluster. Five of the six individuals were female and for most, symptoms were getting worse, with none reporting symptom improvement.

\section{Discussion}

Eight distinct clusters comprised of UEMSD symptoms were formulated in a dataset of RSI patients. Most clusters consisted of diffuse rather than localized symptoms, in contrast to our initial hypothesis. The exception was mild bilateral aching stiff neck and shoulders (cluster 2). By and large the clusters were distinguished by severity and quality, rather than locality, of symptoms. 
On average, the study patients experienced a symptom intensity of slightly more than "just sensible" dull aching pain in the neck, and right shoulder, lower arm and wrist, stiffness in the neck and right shoulder and wrist, and wrist paraesthesias and coldness. Cluster severity ranged from mild through extreme as compared with these overall mean symptom intensities. Most of the RSI patients experienced mild symptoms; cluster sizes were smaller as symptom severity increased.

In the largest cluster, consisting of almost $40 \%$ of subjects (cluster 1), members had mild symptoms of relatively short duration (a mean of 2.5 years). At the time of the survey, three-fourths in this cluster were working and almost half were improving. Another $25 \%$ of the patient association members had localized mild bilateral neck and shoulder symptoms consistent with tension neck syndrome [37] and possibly trapezius myalgia [38] (cluster 2). Clusters 3 and 5 were characterized by symptoms of moderate intensity (total prevalence $=26.5 \%$ ).

Based on symptom qualities, there appeared to be two types of non-specific more severe MSDs (total prevalence $=10.1 \%$ ). The first was a type which was dominated by pain (cluster 7-extreme diffuse MSD with highlighted pain). The second was a type dominated by coldness, numbness and paraesthesias (cluster 6-severe diffuse MSD with highlighted CNP, cluster 8-extreme diffuse MSD with highlighted CNP). Interestingly, among those with the most extreme symptoms, clusters 7 and 8 , the latter group is characterized by relatively short ( 2.3 years) symptom duration with half of the cluster members working. It is possible that the predominance of coldness, numbness, and paraesthesias rather than pain has allowed many of these patients to continue their employment.

The diffuse nature of the clusters we identified indicates the possible incompleteness of conventional case definitions for work-related upper extremity morbidity, which tend to be localized to particular anatomical areas. Mackinnon and Novak [39] describe a non-specific upper extremity pain syndrome upon which symptoms specific to a particular cumulative trauma disorder (such as CTS) are superimposed, of which cluster 5 appears to be an example. Other physicians have noted diffuse symptoms in office workers, an occupational group which accounts for nearly half of the present sample [40, 41]. Bilateral pain, widespread pain, and pain in contiguous anatomical sites greater than to be expected given an assumption of independence between sites have been found in the general population $[2,42]$ and in workers [43]. Moreover, practicing clinicians have observed that UEMSD symptoms seem to become more diffuse with time $[44,45]$. Various theories have been proposed to explain such widespread symptoms, including a positive feedback mechanism of spreading muscle overuse/underuse [39] and peripheral or central sensitization [46-48]. Supporting evidence has been found in an animal model [49].

This point prevalence study lends support to prior clinical reports describing anatomically diffuse symptoms among patients with UEMSDs. In our study, diffuse symptoms are found in a majority of patients at a mean duration of 3.25 years from symptom onset. In light of these findings, development of patient assessment tools in both clinical and research settings should routinely incorporate information on symptom pattern and duration. Such information can help to reformulate clinical case definitions, diagnostic categories, prognostic indicators and, ultimately, help to improve clinical management, including occupational rehabilitation.

To our knowledge, this study is unique in examining symptom qualities in UEMSD patients in such detail. We are aware of only one other author who has conducted cluster analyses in UEMSD patients. Reading et al. [50, 51] performed three separate cluster analyses based predominantly on physical examination signs in the wrist/hand, shoulder and elbow in working age adults with and without upper extremity pain. In the hand/wrist as well as in the elbow region, cluster analyses were based primarily on severity and location, whereas the shoulder clusters were formed on the basis of severity only. It is unknown how many of the patients in their sample had involvement in more than one anatomical region. As our data relied on symptoms only, it is difficult to make a comparison with these findings.

The formulated clusters were not identical with respect to gender composition. As UEMSD severity increased, so generally did the proportion of females in the associated cluster. Musculoskeletal symptom severity (due to more prevalent exposure to work and non-work risk factors) was found to be greater in females than in males in a study of pubic service employees [52]. However, since females may tend to report symptoms in general more easily than males [53], further research would be necessary to confirm an association between MSD symptom severity and gender.

Although small numbers in several clusters prevented adequate comparisons, several clusters differed both by percentage working and by symptom course as compared with the surveyed patient population as a whole. Of these, clusters 5 (moderate MSD with highlighted bilateral elbow shooting stabbing pain) and 7 (extreme diffuse MSD with highlighted pain) were characterized by worsening or stable symptoms and by fewer individuals working. As mentioned previously, cluster 1 (mild diffuse MSD) was composed of more members working with improving symptoms. It should be noted that each of these clusters were characterized by diffuse symptoms. 
Study Limitations

There are several limitations to the study. Brauer et al. [54] found that subjects were able to recall their pain severity over a period of 3 months. Hence, recall of symptoms within the last week would presumably be reliable. Nonetheless, recall bias may have affected respondents' recollection of symptom intensity at the time of onset, depending on whether they were better or worse at the time of the administration of the survey. Current symptom status affects individuals' recall of prior pain; those currently symptomatic may have the tendency to over-recall previous pain at a particular point in time whereas those without symptoms may "forget" or underestimate previous pain at a given occasion [55]. However, it is unknown how this would affect subjects' reporting of their overall symptom course.

The low response rate $(53 \%)$ may indicate a selection bias affecting the results. It is likely that the non-respondents were more impaired than those answering the survey. Although the whole range in intensity or severity of complaints was represented in the final sample, it is likely that this survey may under-represent severe MSDs or that it may underestimate the prevalence of MSDs that impair writing ability (such as MSDs particularly affecting the fingers/ hand/wrist), as these subjects may have been prevented by their symptoms from filling out the questionnaire.

The findings may be specific to the occupational exposures of this particular cohort, which was composed primarily of office workers, with lesser percentages of IT specialists and industrial employees. Clusters based on symptoms alone may be more sensitive to disease states than those based on both signs and symptoms and useful for secondary preventive purposes, yet they may not be specific enough to determine suitable primary prevention in the workplace or treatment options in the clinic.

A strength of the research presented in this paper (that was undertaken to define an empirical classification system for upper extremity MSD symptoms) was the employment of cluster analysis, a classification technique for forming homogenous groups within complex data sets [56]. Cluster analysis aims at the classification of individuals or objects based solely on an internal analysis of similarities and differences in multivariate data patterns [57]. The methodology has found numerous applications in psychology [26, 33, 58]. This approach has also been applied in characterizing Alzheimer's disease [8, 9], systematic lupus erythematosus [59], complex regional pain syndrome [5, 6], Parkinson's disease [60] and other physical disorders.

Notwithstanding such wide use, methodological ambiguities exist in the cluster analysis literature with respect to the choice of similarity measure, recovery capabilities, and replicability of structures. [57]. Our clustering strategy employed the multistage Euclidean grouping (MEG) method described by McDermott [25] that employed Ward's similarity measure and explicitly evaluates its recovery capability and structure replication rate.

\section{Conclusions}

Eight clusters based primarily on symptom quality and severity were formed from a survey of upper extremity MSD patients. The clusters, most of which consisted of diffuse symptomatology, differed with respect to percentage working, gender proportion and symptom course. Future studies should formulate clusters based on detailed symptoms as well as signs in comparable populations. Since the clusters were determined through reports of present symptoms and of symptoms within 1 week of filling out the questionnaire, it is not possible to predict a probable symptom course. Future studies could collect data from health care providers prospectively to determine the possible prognostic value of these clusters with respect to natural history, chronicity, and return to work.

Acknowledgments This study was performed in cooperation with the Dutch RSI patients association. We would like to thank their board and all the patients who were willing to share their experiences. Dr. Gold would like to thank Dr. Laura Punnett for her support of these ideas early in her academic career. Jonathan Dropkin provided useful clinical insight during various stages of manuscript preparation.

Open Access This article is distributed under the terms of the Creative Commons Attribution Noncommercial License which permits any noncommercial use, distribution, and reproduction in any medium, provided the original author(s) and source are credited.

\section{References}

1. Bureau of Labor Statistics. Nonfatal occupational injuries and illnesses requiring days away from work, 2006. Washington: U.S. Department of Labor; 2007.

2. Picavet HS, Schouten JS. Musculoskeletal pain in the Netherlands: prevalences, consequences and risk groups, the DMC(3)study. Pain. 2003;102:167-78.

3. Harrington JM, Carter JT, Birrell L, Gompertz D. Surveillance case definitions for work-related upper limb pain syndromes. Occup Environ Med. 1998;55:264-71.

4. Sluiter JK, Rest KM, Frings-Dresen MH. Criteria document for evaluating the work-relatedness of upper-extremity musculoskeletal disorders. Scand J Work Environ Health. 2001;27(Suppl 1): $1-102$

5. Harden RN, Bruehl S, Galer BS, Saltz S, Bertram M, Backonja $\mathrm{M}$, et al. Complex regional pain syndrome: are the IASP diagnostic criteria valid and sufficiently comprehensive? Pain. 1999;83:211-9.

6. Harden RN, Bruehl S, Stanton-Hicks M, Wilson PL. Proposed new diagnostic criteria for complex regional pain syndrome. Pain Med. 2007;8:326-31. 
7. de Souza JB, Goffaux P, Julien N, Potvin S, Charest J, Marchand S. Fibromyalgia subgroups: profiling distinct subgroups using the Fibromyalgia Impact Questionnaire. A preliminary study. Rheumatol Int. 2009;29:509-15.

8. Armstrong R, Wood L. The identification of pathological subtypes of Alzheimer's disease using cluster analysis. Acta Neuropath. 1994;88:60-6.

9. Stopford C, Snowden J, Thompson J, Neary D. Distinct memory profiles in Alzheimer's disease. Cortex. 2007;43:846-57.

10. Stopford CL, Snowden JS, Thompson JC, Neary D. Variability in cognitive presentation of Alzheimer's disease. Cortex. 2008;44: 185-95.

11. Breckenridge JN. Validating cluster analysis: consistent replication and symmetry. Multivar Behav Res. 2000;35:261-85.

12. Fabrigar LR, Wegener DT, MacCallum RC, Strahan EJ. Evaluating the use of exploratory factor analysis in psychological research. Psychol Meth. 1999;4:272-99.

13. Field A. Discovering statistics using SPSS. 2nd ed. London: Sage; 2005.

14. Tabachnick BG, Fidell LS. Using multivariate statistics. 5th ed. Boston: Pearson; 2007.

15. Gorsuch RL. Factor analysis. 2nd ed. Hillsdale: Lawrence Erlbaum; 1983.

16. Velicer WF, Eaton CA, Fava JL. Construct explication through factor or component analysis: a review and evaluation of alternative procedures for determining the number of factors or components. In: Goffin RD, Helms E, editors. Problems and solutions in human assessment: honoring Douglas N. Jackson at seventy. New York: Guilford; 2000. p. 41-71.

17. Zwick WR, Velicer WF. Comparison of five rules for determining the number of components to retain. Psychol Bull. 1986; 99:43.

18. Cattell RB. The scree test for the number of factors. Multivar Behav Res. 1966;1:245-76.

19. Glorfeld LW. An improvement on Horn's parallel analysis methodology for selecting the correct number of factors to retain. Educ Psychol Meas. 1998;55:377-93.

20. Horn J. A rational and test for the number of factors in factor analysis. Psychometrika. 1965;30:179-85.

21. Gregory RJ. Psychological testing: history, principles, and applications. 5th ed. Boston: Pearson; 2007.

22. Salvia J, Ysseldyke JE. Assessment in special and inclusive education. 9th ed. Boston: Houghton Mifflin Company; 2004.

23. Buja A, Eyuboglu N. Remarks on parallel analysis. Multivar Behav Res. 1992;27:509-40.

24. Hair JF Jr, Black WC. Cluster analysis. In: Grimm LG, Yarnold PR, editors. Reading and understanding multivariate statistics. Washington: American Psychological Association; 2000. p. 147205.

25. McDermott PA. MEG: Megacluster analytic strategy for multistage hierarchical group with relocations and replications. Educ Psychol Meas. 1998;58:677-86.

26. Henry DB, Tolan PH, Gorman-Smith D. Cluster analysis in family psychology research. J Family Psych. 2005;19:121-32.

27. Mandara J. The typological approach in child and family psychology: a review of theory, methods, and research. Clin Child Family Psychol Rev. 2003;6:129-46.

28. Ward JH Jr. Hierarchical grouping to optimize an objective function. Am Stat Assoc J. 1963;58:236-44.

29. Worrell FC, Vandiver BJ, Schaefer BA, Cross WE, FhagenSmith PE. Generalizing nigrescence profiles: cluster analysis of cross racial identity scale (CRIS) scores in three independent samples. Counsel Psychol. 2006;34:519-47.

30. Tryon RC, Bailey DE. Cluster analysis. New York: McGraw Hill; 1970.
31. Cormack RM. A review of classification. J R Stat Soc (Ser A). 2005;134:321-67.

32. Cattell RB. Rp and other coefficients of pattern similarity. Psychometrika. 1949;14:279-98.

33. Glutting JJ, McDermott PA, Konold TR. Ontology, structure, and diagnostic benefits of a normative subtest taxonomy from the WISC-III standardization sample. In: Flanagan DP, Genshaft JL, Harrison PL, editors. Beyond traditional intellectual assessment: contemporary and emerging theories, tests, and issues. New York: Guilford; 1997. p. 349-72.

34. Glutting JJ, McGrath EA, Kamphaus RW, McDermott PA. Taxonomy and validity of subtest profiles on the Kaufman Assessment Battery for Children. J Special Educ. 1992;26:85115.

35. Konold TR, Glutting JJ, McDermott PA, Kush JC, Watkins MM. Structure and diagnostic benefits of a normative subtest taxonomy developed for the WISC-III standardization sample. J School Psychol. 1999;37:29-48.

36. Konold TR, Glutting JJ, McDermott PA, Woodcock RW. The development and applied utility of a normative aptitudeachievement taxonomy for the WJ-R. J Spec Educ. 1997;31: 212-32.

37. Van Eerd D, Beaton D, Cole D, Lucas J, Hogg-Johnson S, Bombardier C. Classification systems for upper-limb musculoskeletal disorders in workers: a review of the literature. J Clin Epid. 2003;56:925-36.

38. Larsson B, Sogaard K, Rosendal L. Work related neck-shoulder pain: a review on magnitude, risk factors, biochemical characteristics, clinical picture and preventive interventions. Best Pract Res Clin Rheumatol. 2007;21:447-63.

39. Mackinnon SE, Novak CB. Clinical commentary: pathogenesis of cumulative trauma disorder. J Hand Surg. 1994;19A:873-83.

40. Pascarelli EF, Hsu YP. Understanding work-related upper extremity disorders: clinical findings in 485 computer users, musicians, and others. J Occup Rehabil. 2001;11:1-21.

41. Jepsen JR. Upper limb neuropathy in computer operators? A clinical case study of 21 patients. BMC Musculoskelet Disorders. 2004;5:26.

42. Walker-Bone K, Reading I, Coggon D, Cooper C, Palmer KT. The anatomical pattern and determinants of pain in the neck and upper limbs: an epidemiologic study. Pain. 2004;109:45-51.

43. Haukka E, Leino-Arjas P, Solovieva S, Ranta R, Viikari-Juntura E, Riihimaki H. Co-occurrence of musculoskeletal pain among female kitchen workers. Int Arch Occup Environ Health. 2006; 80:141-8.

44. Miller BM, Topliss DJ. Chronic upper-limb pain syndrome (repetitive strain injury) in the Australian workforce: a systemic cross sectional rheumatological study of of 229 patients. J Rheumatol. 1988; 15:1705-12.

45. Marinus J, Van Hilten JJ. Clinical expression profiles of complex regional pain syndrome, fibromyalgia and a-specific repetitive strain injury: more common denominators than pain? Disab Rehab. 2006;28:351-62.

46. Johansson H, Sojka P. Pathophysiological mechanisms involved in genesis and spread of muscular tension in occupational muscle pain and in chronic musculoskeletal pain syndromes: a hypothesis. Med Hypothesis. 1991;35:196-203.

47. Hutson MJ. Work-related upper limb disorders: recognition and management. Boston: Reed Educational and Professional Publishing; 1997.

48. Arendt-Nielsen L, Graven-Nielsen T. Muscle pain: sensory implications and interaction with motor control. Clin $\mathrm{J}$ Pain. 2008;24:291-8.

49. Elliott MB, Barr AE, Clark BD, Amin M, Amin S, Barbe MS. High force reaching task induces widespread inflammation, 
increased spinal cord neurochemicals and neuropathic pain. Neurosci. 2009;158:922-31.

50. Reading I, Walker-Bone K, Palmer K, Coggon D, Cooper C. Classification algorithms for musculoskeletal disorders of the wrist and hand. In: International scientific conference on prevention of work-related musculoskeletal disorders. Amsterdam: PREMUS; 2001.

51. Reading I, Walker-Bone K, Palmer K, Coggon D, Cooper C. Classification algorithms for musculoskeletal disorders of the shoulder and elbow. In: International scientific conference for the prevention of work-related musculoskeletal disorders. Amsterdam: PREMUS; 2001.

52. Strazdins L, Bammer G. Women, work and musculoskeletal health. Soc Sci Med. 2004;58:997-1005.

53. Punnett L, Herbert R. Work-related musculoskeletal disorders: is there a gender differential, and if so, what does it mean? In: Goldman M, editor. Women and health. New York: Academic Press; 2000. p. 474-92.

54. Brauer C, Thomsen JF, Loft IP, Mikkelsen S. Can we rely on retrospective pain assessments? Am J Epidemiol. 2003;157:552-7.
55. Miranda H, Gold JE, Gore R, Punnett L. Recall of prior musculoskeletal pain. Scand J Work Environ Health. 2006;32:294-9.

56. Borgen FH, Barnett DC. Applying cluster analysis in counseling psychology research. J Consult Psychol. 1987;34:456-68.

57. Overall JE, Gibson JM, Novy DM. Population recovery capabilities of 35 cluster analysis methods. J Clin Psychol. 1993; 49:459-70.

58. Atkinson TM, Konold TR, Glutting JJ. Patterns of memory: a normative taxonomy of the Wide Range Assessment of Memory and Learning-Second Edition (WRAML-2). J Int Neuropsychol Soc. 2008;14:869-77.

59. Jacobsen S, Petersen J, Ullman S, Junker P, Voss A, Rasmussen J, et al. A multicentre study of 513 Danish patients with systemic lupus erythematosus. I. Disease manifestations and analyses of clinical subsets. Clin Rheumatol. 1998;17:468-77.

60. Reijnders JS, Ehrt U, Lousberg R, Aarsland D, Leentjens AF. The association between motor subtypes and psychopathology in Parkinson's disease. Parkinsonism Relat Disord. 2009;15:379-82. 